\title{
A influência da família na escolha da mulher pelo parto domiciliar planejado
}

\author{
Family influence over women's choice for planned home birth \\ La influencia de la familia en la decisión de las mujeres por el parto planificado en casa
}

Recebido: 31/05/2021 | Revisado: 07/06/2021 | Aceito: 10/06/2021 | Publicado: 23/06/2021

\author{
Thais Mesquita Muros \\ ORCID: https://orcid.org/0000-0003-3341-7198 \\ Secretaria de Saúde de Rio das Ostras, Brasil \\ E-mail: thaismmuros@gmail.com \\ Jane Baptista Quitete \\ ORCID: https://orcid.org/0000-0003-0330-458X \\ Universidade Federal Fluminense, Brasil \\ E-mail: janequitete@gmail.com \\ Ricardo José Oliveira Mouta \\ ORCID: https://orcid.org/0000-0002-1284-971X \\ Universidade do Estado do Rio de Janeiro, Brasil \\ E-mail: ricardomouta@hotmail.com \\ Beatriz Garcia de Souza \\ ORCID: https://orcid.org/0000-0002-4071-4601 \\ Universidade Federal Fluminense, Brasil \\ E-mail: garcias.beatriz97@gmail.com \\ Marcilene Andrade Ribeiro Marins \\ ORCID: https://orcid.org/0000-0002-9483-7666 \\ Secretária Municipal de Saúde de Macaé, Brasil \\ E-mail: marcilenearibeiro@gmail.com \\ Octavio Muniz da Costa Vargens \\ ORCID: https://orcid.org/0000-0001-8975-480X \\ Universidade do Estado do Rio de Janeiro, Brasil \\ E-mail: octavargens@gmail.com
}

\begin{abstract}
Resumo
Conhecer a influência da família sobre a escolha das mulheres pelo parto domiciliar planejado. É um estudo descritivo exploratório, de abordagem qualitativa. Os dados foram coletados através de entrevistas semiestruturadas, gravadas, transcritas e submetidas à análise de conteúdo. A amostra, obtida por meio de saturação de dados, foi composta por 6 mulheres que tiveram pelo menos um dos seus filhos por parto domiciliar planejado, em cidades do estado do Rio de Janeiro. Emergiram duas categorias temáticas: Tentativas de convencimento da família e Apoio do parceiro como fator determinante na escolha da mulher pelo parto domiciliar. O empoderamento, segurança e autoestima são desfechos importantes quando há apoio do parceiro, muito mais do que com outros membros da família.
\end{abstract}

Palavras-chave: Parto domiciliar; Enfermagem Obstétrica; Tomada de decisões; Relações familiares; Saúde da mulher.

\begin{abstract}
To get to know the family influence over women's choice for planned home birth. It is an exploratory descriptive research, a qualitative approach. Data was collected through semi structured interviews, recorded, transcribed and submitted to content analysis. The sample, obtained through data saturation, was composed by six women that delivered at least one child in a planned home birth, in cities in the state of Rio de Janeiro. Emerged two subject fields: family convincing attempt and partner support as a decisive factor in woman's choice for planned home birth. Empowering, safety and self-esteem are important outcomes when there is support from the partner, much more than other family members.

Keywords: Home childbirth; Obstetric Nursing; Decision making; Family relations; Women's health.

\section{Resumen}

Conocer la influencia de la familia en la decisión de las mujeres por el parto planificado en casa. És un estudio exploratorio descriptivo con abordaje cualitativo. Los datos fueron recogidos mediante entrevistas semiestructurada, grabados, transcriptos y sometidos a análisis de contenido. La muestra, obtenida mediante saturación de datos estuvo compuesta por 6 mujeres que tuvieron al menos uno de sus hijos por parto planificado en casa, en ciudades del estado de Rio de Janeiro. Surgieron dos categorías temáticas: intento de convencer a la familia y apoyo de la pareja como factor determinante en la decisión de la mujer para el parto en casa. El empoderamiento, seguridad y autoestima son resultados importantes cuando hay apoyo de la pareja, mucho más que de otros miembros de la familia.

Palabras clave: Parto domiciliario; Enfermería obstétrica; Toma de decisiones; Relaciones familiares; Salud de la mujer.
\end{abstract}




\section{Introdução}

O parto domiciliar planejado tem sido uma opção às mulheres frente ao modelo de atenção ao parto atual (Quitete, 2015). Em nosso país, o Ministério da Saúde propôs programas e políticas com vistas a assumir compromissos com a garantia dos direitos sexuais e reprodutivos das mulheres e crianças (Quitete \& Monteiro, 2018).

$\mathrm{Na}$ cultura ocidental o ambiente hospitalar aparenta ser um local de excelência para a ocorrência do parto, visto o surgimento de novas tecnologias duras consideradas seguras e eficazes para a mulher e criança. Mesmo diante de todo aparato tecnológico observa-se que as mulheres não têm sido protagonistas do próprio parto, não possuem o poder de decisão e são submetidas a procedimentos muitas vezes desnecessários (Sanfelice \& Shimo, 2015). A mulher perdeu privacidade e autonomia, foi separada da família e submetida a normas institucionais e práticas intervencionistas sem o devido esclarecimento e consentimento (Vargens et al., 2016).

Com o intuito de contrapor esta situação, surge um novo paradigma denominado cuidado humanístico e consequentemente, o conceito de Humanização do Parto propondo que a atuação do profissional de saúde respeite os aspectos da fisiologia, não intervenha desnecessariamente, reconheça os aspectos sociais e culturais do parto e do nascimento, promova a saúde e ofereça o suporte emocional necessário à mulher e sua família, facilitando a formação dos laços afetivos familiares e o vínculo mãe-bebê (Dias et al. 2016).

Apesar do parto domiciliar planejado ser uma prática reconhecida e legitimada no Brasil, e em diversos países, como o Canadá, a Holanda e a Austrália, este modelo de atendimento ainda está em expansão no Brasil (Brasil, 2016; Mattos et al. 2016; Sanfelice \& Shimo, 2015).

O parto domiciliar planejado tem se popularizado e tem se baseado em evidências científicas e alicerçado principalmente no respeito às decisões femininas, possibilitando um cuidado centrado na mulher, principalmente do ponto de vista da autonomia, as quais estão relacionadas à participação mais ativa da mulher (Reis, 2017).

Frente a esta problemática indaga-se: Qual a influência da família sobre a escolha das mulheres pelo parto domiciliar planejado? Com o intuito de responder as indagações deste estudo traçou-se como objetivo: analisar como a família influencia na escolha das mulheres pelo parto domiciliar planejado.

\section{Metodologia}

Pesquisa de abordagem qualitativa, exploratória e descritiva, realizada em 2015 por meio de um instrumento com dados referente à caracterização sociodemográfica e obstétrica, juntamente com uma entrevista semiestruturada gravada, composta por perguntas abertas.

As participantes foram selecionadas por meio da técnica snowball, método de amostragem que permite a definição de uma amostra por meio das indicações procedidas por pessoas que conhecem outras com características em comum de interesse do estudo (Goodman, 1961). O ponto de partida ocorreu com enfermeiras obstétricas que indicaram mulheres acompanhadas por elas no estado do Rio de Janeiro.

Os critérios de inclusão foram: ter tido pelo menos um dos seus filhos por parto natural em casa, o parto ter sido assistido por Enfermeira Obstétrica no estado do Rio de Janeiro, aceitar voluntariamente participar da pesquisa, ter tido o pai como acompanhante do trabalho de parto e parto, ter mais de 18 anos de idade.

A pesquisa atendeu a todas as recomendações da resolução no 466/2012 do Conselho Nacional de Saúde. Tendo sido submetida e aprovada pelo Comitê de Ética em Pesquisa da Universidade Estadual do Rio de Janeiro/UERJ/SR2, parecer $N^{o}$ $032 / 2012$.

Resultados analisados segundo análise de conteúdo temática, que revelou duas categorias temáticas que responderam 
ao objeto de pesquisa: "tentativas de convencimento da família" e "apoio do parceiro como fator determinante na escolha da mulher pelo parto domiciliar" (Bardin, 2016).

Este estudo faz parte da tese de doutorado, intitulada Atribuindo significados as enfermeiras obstétricas: uma construção social sob a ótica das usuárias na perspectiva do interacionismo simbólico (Quitete, 2015).

\section{Resultados}

\section{Caracterização sociodemográfica e obstétrica}

A faixa etária das mulheres variou de 26 a 38 anos, sendo predominante o intervalo entre 31-38 anos de idade $(83,3 \%)$. Todas as participantes possuíam ensino superior completo, se autodeclararam brancas, com atividade remunerada e casada. A maior parte das mulheres eram primíparas $(83,3 \%)$, tendo somente uma secundípara $(16,7 \%)$ já com experiência em parto domiciliar planejado no primeiro filho.

\section{Tentativas de convencimento da família}

As mulheres, a partir de vivencias e experiências negativas sobre a atenção ao parto no modelo medicalizado, assumem suas próprias histórias e fazem escolhas.

Refletindo sobre a minha maior motivação de escolher o parto domiciliar, eu acho que foi pela assistência que eu via no hospital, as mulheres eram maltratadas, as enfermeiras gritavam com elas. Então eu sabia que eu queria qualquer coisa, qualquer coisa, menos parir dentro do hospital. (E 06)

A escolha pelo parto domiciliar planejado é considerada benéfica ao protagonismo feminino na cena do parto.

Então falei pra mim mesma: Dane-se! Eu vou fazer parto normal! Se eu vou aguentar ou não, isso vai ser um problema só meu! A cesárea fica pra vida toda, você leva um corte pra vida toda. Foi a minha melhor escolha. (E 03)

Algumas relatam a desaprovação da família sobre sua escolha pelo parto domiciliar.

Ninguém aprovava muito não, só meu pai que aprovou o parto em casa, o resto falava que eu era uma louca. Falavam assim "maluca de ter parto em casa, você é enfermeira, como que uma enfermeira querer parir em casa. (E 06)

A possibilidade de vivenciar o parto domiciliar é reforçado quando a mulher possui contato com pessoas que já tiveram essa experiência ou com profissionais de confiança que garantem a segurança do parto domiciliar, auxiliando a tomada de decisão e facilitando o processo de empoderamento.

E1 mencionou "Acho que, o que influenciou na minha escolha, foi o fato da minha irmã já trabalhar nessa área. A minha irmã vivenciando essa questão de obstetrícia, ginecologia... Você tem uma referência."

As experiências positivas de partos domiciliares planejados na própria família e os aspectos culturais foram demonstradas em depoimento onde o mesmo sempre foi visto como a melhor opção de parir.

Eu tenho um irmão que nasceu em casa porque meu pai tinha essa visão de que tinha que ir para o hospital. Com minha primeira irmã, minha mãe foi para o hospital e foi muito mal tratada pela estrutura geral, pelo sistema. [...] Eu 
ouvi histórias de uma avó parteira que se orgulhava de quantos nasciam pela mão dela, e eu tenho um monte de primos que não tem meu sangue, que se declaram irmãos da minha mãe, primos não, tios. (E 02)

Não é tarefa fácil promover mudança de opinião sobre local para parir que não seja o hospital, mesmo assim observamos no depoimento das participantes o quanto elas investiram nesta mudança. E algumas obtiveram êxito como é relatado abaixo.

A primeira pequena grande batalha foi tentar fazer meu marido a entrar nessa onda comigo, e apesar de ser um cara totalmente relax houve "uma certa" resistência. Mas como diz o ditado "Água mole em pedra dura...", acabei com a resistência e tive nele o meu maior incentivo. (E 03)

Há um convencimento dos parceiros por parte das mulheres, através da obtenção e compartilhamento de informações, do diálogo, e da presença deles nos encontros de gestantes e nas consultas pré-natal.

Ele [parceiro] até que aceitou mais fácil, porque ele conversou muito com a enfermeira. Então, eu marcava a vinda delas na minha casa para o pré-natal no dia que ele pudesse estar junto, pra ele participar, pra elas [enfermeiras] explicarem tudo pra ele. (E 04)

Esse convencimento ocorreu com todas as entrevistadas e este fato foi considerado determinante para que essas mulheres realmente conseguissem alcançar seus objetivos e levar adiante a realização pessoal de vivenciar o parto domiciliar planejado.

E3 mencionou "A minha família e a do meu marido, que apesar de acharem se tratar de mais uma sandice minha, no final nos deram o maior apoio."

\section{Apoio do parceiro como fator determinante na escolha da mulher pelo parto domiciliar}

$\mathrm{O}$ apoio dos parceiros foi importante na escolha do parto domiciliar planejado para as depoentes. E5 mencionou "Nossa, a participação do meu marido foi fantástica. Ele participou de tudo ativamente. Ele curtiu muito. Ele achava que na hora não ia aguentar, mas me dava o maior apoio."

Ademais, observou-se que por vezes a escolha pelo parto domiciliar planejado foi proposto pelo próprio parceiro.

$\mathrm{Na}$ verdade a ideia do parto em casa foi dele [parceiro]. Quando soube que eu estava grávida, a primeira coisa que veio na minha cabeça foi cesárea. Aí, ele [parceiro] falou "ah esse não é o jeito que se nasce, vamos tentar uma coisa mais natural". Ele [parceiro] deu a ideia de fazer o parto em casa. (E 03)

Os partos assistidos no domicílio propiciam uma maior participação paterna, além de promover maior domínio e controle da situação pelo casal, sensação de liberdade e responsabilidade, motivos que levam casais a optarem pelo parto assistido em casa.

E5 menciona "Ele [parceiro] virou maior defensor do parto domiciliar. Fica fazendo propaganda pra todo mundo que é a melhor coisa que tem. Pra mim foi fundamental o papel do HH [parceiro]." 
Vale ressaltar que o profissional habilitado a assistir parto domiciliar planejado no Brasil é a Enfermeira Obstétrica, e isto causou estranhamento para as mulheres e parceiros e que foi superado logo que tiveram os primeiros encontros durante a consulta pré-natal.

E aí, a gente [eu e meu parceiro] resolveu ir à consulta de pré-natal. E desde a primeira consulta a gente teve certeza que seria com ela [enfermeira]. Sentimos confiança em escolher ela. Não tivemos dúvidas em momento nenhum. A gente nem procurou mais ninguém. (E 01).

\section{Discussão}

O desejo das mulheres em vivenciar a gestação e o parto como eventos fisiológicos são corroborados por diversos estudos, e revela à busca por um cuidado diferenciado daquele prestado no cenário tradicional hospitalar, esta prática reflete a busca de estratégias para fugir da falta de autonomia e do medo que as mulheres sentem de não estarem no controle durante a vivência do processo parturitivo (Leal et al. 2019; Reis, 2017; Souza et al. 2014).

O ambiente domiciliar é um fator determinante para um progresso favorável do processo parturitivo, uma vez que em seus lares essas mulheres se sentem mais confortáveis e com maior protagonismo. Além do fato de este ambiente já proporcionar um contexto familiar de segurança e liberdade, corroborando para uma criação de vínculo familiar desde o momento do parto (Silva et al., 2021; Mocheuti et al., 2020).

As mulheres são vistas pelos familiares com desconfiança, como alguém que colocou a própria vida e a vida do bebê em risco. Para muitas delas, a escolha assumiu contornos de uma escolha clandestina, e foram adjetivadas como louca, maluca, alternativa e irresponsável (Castro, 2015). Por estes motivos, algumas mulheres optam por esconder da família a escolha pelo parto domiciliar planejado (Lessa et al., 2014; Mattos et al., 2016).

Vale destacar, que em nossa sociedade patriarcal as mulheres não têm poder decisório. Mesmo no campo da saúde, onde são reconhecidas como detentoras do poder, a participação efetiva nas decisões ainda não faz parte do cotidiano da maioria das mulheres. Nesse sentido, fica evidente uma nova relação de poder se estabelece quando há a escolha pelo local do parto é posto pela mulher (Lessa et al., 2014).

Há famílias que optam pelo modelo naturalista, mas que na relação com o movimento naturalista diferem no sentido de possuir certa independência em relação ao que pensam e como agem. Evidenciando, assim, aspectos importantes nos seus valores acerca do parto domiciliar instituído na visão humanizada perante a analogia da relação com o meio ambiente (Lessa et al., 2014).

Algumas mulheres, ao se depararem com percepções negativas da família, desenvolvem rituais de separação, interrompendo, mesmo que temporariamente, os vínculos com redes sociais, e até mesmo alguns familiares, como estratégia de proteção. Quando tomam atitudes de ruptura, reafirmam a ideia de que as decisões relacionadas ao parto interessam apenas a intimidade familiar (Prates et al., 2018).

A participação do parceiro traz um misto de sentimentos não só para o homem, mas principalmente na mulher que se sente mais segura e preparada para esse momento especial, além de estimular a criação de vínculo pai/mãe/filho (Carvalho et al., 2017). A mulher necessita de apoio contínuo durante o parto e, quando esse apoio é dado por um membro da família, as mulheres têm uma avaliação do parto mais positiva, sentem-se mais satisfeitas e felizes (Quitete \& Monteiro, 2018).

Os parceiros mostram uma atitude de respeito e apoio a decisão da mulher pelo parto domiciliar planejado, isto denota reconhecimento da companheira como protagonista do parto (Lessa et al., 2014; Martinez et al., 2015; Rodrigues et al., 2018). Algumas depoentes enfatizaram que a atitude adotada pelo parceiro seria determinante, pois se tivessem expressado sentimentos de repulsa ou negatividade não teria sido possível realizá-lo (Martinez et al., 2015). 
Ressaltamos que, é significativo para a mulher, neste processo de escolha pelo local do parto, o reconhecimento de que a decisão pertence mais a mulher do que ao homem, pelo fato de que é a mulher quem vivencia o processo. Este autoconhecimento faz parte do processo de empoderamento feminino (Lessa et al., 2014; Prates et al., 2018).

As práticas de cuidado das Enfermeiras Obstétricas são consideradas promotoras da autonomia da mulher no processo de parto e nascimento. Estas se utilizam do conhecimento científico e de tecnologias de cuidado pautados no modelo humanístico (Mattos et al., 2016; Reis et al., 2017).

\section{Conclusão}

O estudo retrata a importância do apoio frente à tomada de decisão da mulher pelo parto domiciliar planejado. Houve o empoderamento, segurança e autoestima na presença de apoio do parceiro, muito mais do que com outros membros da família. A enfermagem obstétrica, principalmente aquelas que atuam no domicílio, propicia um cuidado libertador, que estimula a autonomia e empoderamento feminino, em toda sua capacidade seja física ou psíquica.

Destacam-se, como limitações deste estudo, as reduzidas produções científicas sobre o tema e amostra, a qual não representa o universo do fenômeno investigado, impedindo, assim, a generalização dos achados. Entretanto, os resultados desta pesquisa refletem uma realidade local, e pode subsidiar novas pesquisas.

Embora com suas limitações, este estudo se mostra relevante, apontando questões que auxiliarão na melhoria da assistência da enfermagem obstétrica, corroborando para uma maior disseminação de informações para as mulheres gestantes que buscam realizar um parto domiciliar e sua rede de apoio, a família. Como já demonstrado anteriormente, é um tema que ainda sofre com a baixa produção científica, por isso incentiva-se estudos acerca do tema a nível nacional para que se possa compreender em sua totalidade a dinâmica do tema no país.

\section{Referências}

Bardin, L. (2016). Análise de conteúdo (70a ed.).

Brasil. Ministério da Saúde. Secretaria de Ciência, Tecnologia e Insumos Estratégicos. Departamento de Gestão e Incorporação de Tecnologias em Saúde, B. (2017). Diretrizes nacionais de assistência ao parto normal: versão resumida https://bvsms.saude.gov.br/bvs/publicaco es/diretrizes_nacionais_assistencia_parto_normal.pdf

Castro, C. M. (2015). Os sentidos do parto domiciliar planejado para mulheres do município de São Paulo, Sao Paulo. Cadernos Saúde Coletiva, 23(1), 6975. https://doi.org/10.1590/1414-462x201500010012

Carvalho, I. D., Carvalho, C. F., Enders, B. C., \& Brito, R. S. (2017). A participação do homem durante o Nascimento do filho: Videos do YouTube [Men's participation during childbirth: YouTube videos] [La participación del hombre durante el nacimiento del hijo: videos de YouTube]. Revista Enfermagem UERJ, 25(0). https://doi.org/10.12957/reuerj.2017.11474

Dias, E., Monção, P., Cerqueira, N. C., \& Souza, M. A. (2016). Assistência de enfermagem no parto normal em um hospital público de Espinosa, Minas Gerais, sob a ótica da puérpera. Revista Interdisciplinar. https:// https://revistainterdisciplinar.unino vafapi.edu.br/index.php/revinter/article/viewFile/910/pdf_310

Goodman, L. (1961). Snowball Sampling. Ann. Math. Statist. https://doi.org/DOI: 10.1214/aoms/1177705148

Leal, M. D., $\quad$ Bittencourt, S. D., $\quad$ Pereira, A. P., $\quad$ Ayres, B. V., Silva, L. B., $\quad$ Thomaz, E. B., Lamy, Z. C., Pereira, M., $\quad$ Torres, J. A., $\quad$ Gama, S. G., Domingues, R. M., \& Vilela, M. E. (2019). Avanços Na assistência AO parto no Brasil: Resultados preliminares de dois estudos avaliativos. Cadernos de Saúde Pública, 35(7). https://doi.org/10.1590/0102-311x00223018

Lessa, H. F., Tyrrell, M. A., Alves, V. H., \& Rodrigues, D. P. (2014). Social relations and the option for planned home birth: An institutional ethnographic study. Online Brazilian Journal of Nursing, 13(2). https://doi.org/10.5935/1676-4285.20144163

Martínez, T., Ruiz, C., González, J., Peralvo, M., \& Pérez, G. (2015). The father's decision making in home birth. Investigación y Educación em Enfermería, 33(3). https://doi.org/10.17533/udea.iee.v33n3a22

Mattos, D., Vandenberghe, L., \& Martins, C. (2016). O enfermeiro obstetra no parto domiciliar planejado. Rev. enferm. UFPE on line. https://periodicos.ufpe.br/revistas/revistaenfermagem/index.php/revista/article/view/8587/pdf_9596

Mocheuti, K. N., Zamboni, S. D., Silva, R. A., Rocha, R. P., Silvestre, G. C., \& Borges, A. P. (2020). Os significados atribuídos pela mulher AO trabalho das enfermeiras obstetras no parto domiciliar planejado. Research, Society and Development, 9(10), e019108237. https://doi.org/10.33448/rsd-v9i10.8237 
Research, Society and Development, v. 10, n. 7, e33510716665, 2021

(CC BY 4.0) | ISSN 2525-3409 | DOI: http://dx.doi.org/10.33448/rsd-v10i7.16665

Prates, L. A., Timm, M. S., Wilhelm, L. A., Cremonese, L., Oliveira, G., Schimith, M. D., \& Ressel, L. B. (2018). Being born at home is natural: Care rituals for home birth. Revista Brasileira de Enfermagem, 71(suppl 3), 1247-1256. https://doi.org/10.1590/0034-7167-2017-0541

Quitete, J. B. (2015). Atribuindo significados as enfermeiras obstétricas: uma construção social sob a ótica das usuárias na perspectiva do interacionismo simbólico [Doctoral dissertation]. http://www.bdtd.uerj.br/tde_busca/arquivo.php?codArquivo=8674

Quitete, J. B., \& Monteiro, J. A. (2018). A participação do pai no parto domiciliar planejado: Um ato significativo para a mulher. Revista Enfermagem UERJ, 26, e18682. https://doi.org/10.12957/reuerj.2018.18682

Reis, T. L., Padoin, S. M., Toebe, T. R., Paula, C. C., \& Quadros, J. S. (2017). Autonomia feminina no processo de parto E Nascimento: Revisão integrativa Da literatura. Revista Gaúcha de Enfermagem, 38(1). https://doi.org/10.1590/1983-1447.2017.01.64677

Rodrigues, T., Monteschio, L., Cismer, E., Decesaro, M., Serafim, D., \& Marcon, S. (2018). Motivations for planned home birth: an exploratory descriptive study. Online Brazilian Journal of Nursing. https://doi.org/10.17665/1676-4285.20185891

Sanfelice, C., \& Shimo, A. (2015). Home Birth: Understanding The Reasons For This Choice. Texto \& Contexto Enfermagem. https://doi.org/10.1590/010407072015002850014

Silva, R. L., Santo, I. M., Lima, R. S., Silva, H. L., Santos, M. S., Cardoso, M. D., Ananias, M. D., Coelho, A. S., Luz, A. S., Araújo, E. V., Duarte, I. P., Lira, E. V., Santos, J. D., \& Fontes, F. L. (2021). E normal DAR a luz Em Casa: A busca pela revalorização do ambiente domiciliar Como espaço adequado para o momento do parto. Research, Society and Development, 10(5), e11410514598. https://doi.org/10.33448/rsd-v10i5.14598

Souza, R., Soares, L., \& Quitete, J. (2014). Parto natural domiciliar: um poder da natureza feminina e um desafio para a enfermagem obstétrica. Revista Cuidado é Fundamental. https://doi.org/: 10.9789/2175-5361.2014v6n1p118

Vargens, O., Nunes, S., Silva, C., \& Progianti, J. (2016). Procedimentos invasivos no cuidado à parturiente sob a perspectiva de gênero. Revista Enfermagem UERJ. https://doi.org/10.12957/reuerj.2016.15066 